\title{
Clinical Effects of Personalized Dialysate Sodium in Conventional, Quotidian, and Nocturnal Home Hemodialysis Patients: A Randomized Crossover Trial
}

\author{
Benjamin KA Thomson ${ }^{1,2,3 *}$, Lihua Li² and Robert M Lindsay 1,2,3 \\ ${ }^{1}$ Division of Nephrology, Department of Medicine, London Health Sciences Centre and Western University, London, Ontario, Canada \\ ${ }^{2}$ Kidney Clinical Research Unit, London Health Sciences Centre and Western University, London, Ontario, Canada \\ ${ }^{3}$ Department of Medical Biophysics, Western University, London, Ontario, Canada
}

*Corresponding author: Benjamin Thomson, Division of Nephrology, Department of Medicine, 76 Stuart Street, Burr 3-38 Kingston Ontario, K7L-2V7, Canada, Tel: +6135496666; Fax: +613548-2524; E-mail: ben@benthomson.org

Received date: May 21, 2017; Accepted date: June 14, 2017; Published date: June 19, 2017

Citation: Thomson BKA, Li L, Lindsay RM (2017) Clinical Effects of Personalized Dialysate Sodium in Conventional, Quotidian, and Nocturnal Home Hemodialysis Patients: A Randomized Crossover Trial. J Clin Exp Nephrol 1: 38. doi: 10.21767/2472-5056.100038

Copyright: (C) 2017 Thomson BKA, et al. This is an open-access article distributed under the terms of the Creative Commons Attribution License, which permits unrestricted use, distribution, and reproduction in any medium, provided the original author and source are credited.

\section{Abstract}

Background: In thrice weekly conventional haemodialysis patients, higher dialysate sodium concentrations may associate with adverse clinical outcomes. Whether increased frequency and duration of haemodialysis in quotidian and nocturnal patients alters these clinical outcomes is unknown.

Methods: A randomized crossover study was performed in conventional, quotidian and nocturnal haemodialysis patients. Dialysate sodium (Dial- $\mathrm{Na}^{+}$) was personalized 3 $\mathrm{mmol} / \mathrm{L}$ above (DIALHighSOD) or below (DIALLowSOD) the pre-dialysis plasma sodium set point (SP), with 100 days for each crossover study period.

Results: Interdialytic weight gain (IDWG)(2.15 vs. $1.90 \mathrm{~L}$, $\mathrm{p}=0.002)$, IDWG as \% of target weight (IDWG\%)(2.78 vs. $2.39 \%, p=0.002)$, pre-dialysis systolic (143.3 vs. $138.3 \mathrm{~mm}$ $\mathrm{Hg}, \mathrm{p}=0.001)$, diastolic ( 78.6 vs. $75.6 \mathrm{~mm} \mathrm{Hg}, \mathrm{p}=0.008)$ and mean arterial pressure (100.2 vs. $96.5 \mathrm{~mm} \mathrm{Hg}, \mathrm{p}=0.003)$, post-dialysis systolic (135.4 vs. $130.0 \mathrm{~mm} \mathrm{Hg}, \mathrm{p}=0.04)$, diastolic (75.8 vs. $72.4 \mathrm{~mm} \mathrm{Hg}, \mathrm{p}=0.006$ ) and mean arterial pressure (95.7 vs. $91.6 \mathrm{~mm} \mathrm{Hg}, p=0.009$ ) were higher in DIALHighSOD than DIALLowSOD. Haemodialysis frequency was associated with decreased $(R=-0.295$, slope $=-0.002$, $p=0.034)$ IDWG\%, while the opposite was seen with haemodialysis duration ( $R=0.507$, slope $=0.002, p<0.001)$. Haemodialysis duration increased intradialytic change in diastolic blood pressure $(R=0.280$, slope $=1.127, p=0.044)$, while haemodialysis frequency increased post-dialysis diastolic blood pressure $(R=0.366$, slope $=3.464, p=0.008)$.

Conclusions: These results confirm that dialysate sodium concentration alters clinical outcomes in quotidian and nocturnal haemodialysis patients, and that dialysis frequency and duration correlate in opposing fashions in IDWG. Further studies are required to determine the effect of dialysate sodium on cardiovascular outcomes. This trial is registered at UMIN000026102.

\section{Keywords: Dialysate sodium; Hypertension; Interdialytic weight gain; Intradialytic Hypotension; Quotidian haemodialysis; Nocturnal haemodialysis}

\section{Abbreviations:}

BP: Blood Pressure; DialNa+: Dialysate Sodium Concentration; DPNa+: Dialysate To Pre-Dialysis Plasma Sodium Gradient; HIGHDialSOD: Study Period When Dialysate Sodium Is $3 \mathrm{Mmol} / \mathrm{L}$ Greater Than Patient's Sodium Setpoint; IDWG: Interdialytic Weight Gain; LOWDialSOD: Study Period When Dialysate Sodium Is $3 \mathrm{Mmol} / \mathrm{L}$ Lower Than Patient's Sodium Setpoint; PPNa+' PostMinus Pre-Dialysis Plasma Sodium Gradient; Pre-Na+: PreDialysis Plasma Sodium Concentration; Post- $\mathrm{Na}^{+}$: Post-Dialysis Plasma Sodium Concentration; R: Pearson's Correlation Coefficient; SP: Pre-Dialysis Plasma Sodium Setpoint

\section{Introduction}

Cardiovascular death is the leading cause of mortality in haemodialysis patients [1]. A chronic state of volume and pressure overload is a major contributor [2-5] leading to hypertension, left ventricular hypertrophy [6-10], and death $[11,12]$. Considerable research has evaluated the effect of dialysis frequency and duration on clinical outcomes [6,13-15]. It is well established that longer haemodialysis sessions improve outcomes [13,14,16-19] including mortality [20-22]. How this improvement relates to volume and pressure control remains controversial.

In patients undergoing conventional thrice weekly haemodialysis, pre-dialysis plasma sodium is stable over time $[23,24]$ and is thus called sodium set point (SP). When the dialysate sodium concentration exceeds the SP, diffusion of sodium into the patient occurs, and a number of undesirable clinical outcomes result, including increased interdialytic weight gain (IDWG), blood pressure, and ultrafiltration rate [25-30]. These clinical outcomes are predicted by the magnitude not only 
of dialysate to pre-dialysis plasma sodium gradient $\left(\mathrm{DPNa}^{+}\right)$, but also by the post to pre-dialysis plasma sodium gradient $\left(\mathrm{PPNa}^{+}\right)$ [30]. However, the relationship between $\mathrm{DPNa}^{+}$and clinical outcomes remains uncertain in patients who dialyze more than thrice weekly, or longer than four hours per session. Quotidian and nocturnal haemodialysis patients are exposed more frequently and longer to a diffusion gradient; how this alters clinical outcomes has not been prospectively evaluated.

Three objectives were tested in a randomized crossover study. The first objective was to determine how exposure to a higher $\mathrm{DPNa}^{+}$altered IDWG, pre- and post-dialysis blood pressure, and ultrafiltration rate, in a study population that included conventional, quotidian and nocturnal haemodialysis patients. The second objective was to determine the effect of dialysis frequency and duration on each of the same clinical outcomes. The third objective was to establish which of $\mathrm{PPNa}^{+}$or $\mathrm{DPNa}^{+}$ better predicted clinical outcomes.

\section{Materials and Methods}

\section{Study population}

All patients in the home haemodialysis program of the Southwestern Ontario Regional Renal Program were considered. Patients were excluded if they were under the age of 18 , pregnant, or not expected to survive 6 months (Figure 1). All patients used the Fresenius 2008K@homeTM haemodialysis machine.

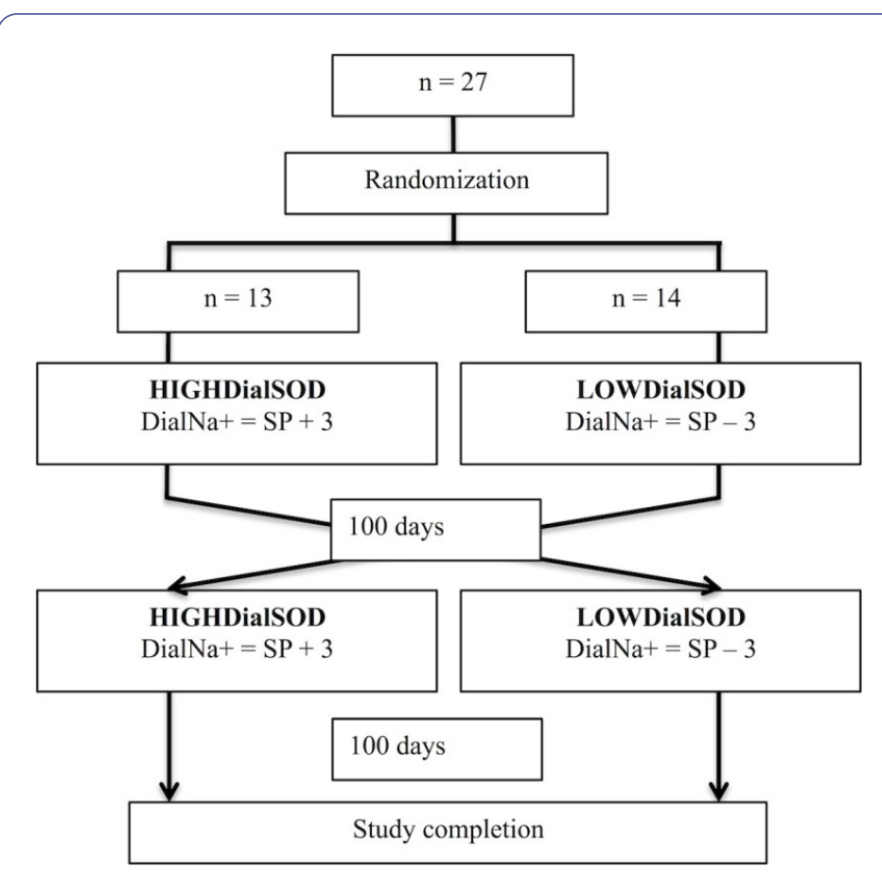

Figure 1: Randomized crossover study design. (DialNa ${ }^{+}=$dialysate $\mathrm{Na}^{+}$concentration $(\mathrm{mmol} / \mathrm{L}) ; \mathrm{SP}=$ pre-dialysis plasma sodium setpoint ( $\mathrm{mmol} / \mathrm{L})$ )

\section{Study design}

A randomized crossover trial design was used (Figure 1). Before randomization, all patients used a standard dialysate sodium concentration of $140 \mathrm{mmol} / \mathrm{L}$. There is no consensus about the number of measurements of pre-dialysis plasma sodium concentration necessary to determine a patient's "set point." However, standard blood work is performed on a monthly basis with study patients. To prevent any single measurement from being weighted too heavily in the determination of this set point, and to assure that the set point was determined from a recent time period when each patient was stable and healthy, the average of the two most recent monthly pre-dialysis plasma sodium (Pre- $\mathrm{Na}^{+}$) measurements defined the patient's sodium setpoint (SP). Patients were randomized to a dialysate sodium (Dial- $\mathrm{Na}^{+}$) concentration group either $3 \mathrm{mmol} / \mathrm{L}$ above (HIGHDialSOD period), or 3 $\mathrm{mmol} / \mathrm{L}$ below (LOWDialSOD period) their SP (Figure 1). Dialysate sodium concentration range was restricted to between 130 and $150 \mathrm{mmol} / \mathrm{L}$, because of concerns of clinical effects. After 100 days, patients crossed over study periods. Patients were followed for another 100 days period, and then the study was completed. The study design did not include a washout period before or between study periods; a similar study confirmed a washout period is not necessary to confirm change in clinical outcomes [31].

Patients were told that dialysate composition was being modified to determine effect on quality of life. A quality of life questionnaire was completed at initiation, middle and end of the study period, but evaluation of the questionnaire was not the study's objective. The QOL survey was used to blind patients to the study objective, so that patients would not focus and modify dietary sodium or water intake. On the other hand, study investigators were not blinded.

\section{Blood sample collection}

Pre-dialysis and post-dialysis blood samples were collected biweekly from the arterial blood line, using a standard slow blood and stop dialysate method. Locking solution ( $2 \mathrm{~mL}$ of $4 \%$ citrate) and a small amount of blood ( 2 to $5 \mathrm{~mL}$ ) are spent prior to blood collection. The samples are centrifuged and refrigerated until delivered to the laboratory, within $12 \mathrm{~h}$ of collection. Of interest in this study were pre-dialysis (Pre- $\mathrm{Na}^{+}$) and post-dialysis (Post- $\mathrm{Na}^{+}$) plasma $\mathrm{Na}^{+}$. Only outpatient blood tests were considered, to eliminate the confounding effect of acute illness.

\section{$\mathrm{Na}^{+}$concentration measurement}

Plasma $\mathrm{Na}^{+}$concentration was measured using Roche Modular P Chemistry Analyzer (Roche Diagnostics, Laval, Quebec, Canada) with indirect ion selective electrodes. Dialysate $\mathrm{Na}+$ concentration was determined using online conductivity measurements in the Fresenius $\mathrm{H}$ series haemodialysis machine. Dialysate conductivity is strongly correlated to dialysate sodium concentration $\left(r^{2}=0.997 ;\right.$ Dialysate $\mathrm{Na}^{+}=9.46 \times$ Dialysate Conductivity+6.5), as previously described [32].

\section{Database creation}

Demographic, clinical and haemodialysis data were collected from the electronic patient record (Power Chart by Cerner), 
home haemodialysis run sheets and the outpatient haemodialysis unit paper chart. Background factors of interest included patient age, sex, diabetes status, height $(\mathrm{cm})$, weight $(\mathrm{kg})$, residual renal function $\left(\mathrm{mL} / \mathrm{min} \times 1.73 \mathrm{~m}^{2}\right)$ and vintage of haemodialysis (days). Residual renal function was calculated as previously described [33]. Haemodialysis records were used to record target weight $(\mathrm{kg})$ and dialysis frequency (sessions per week) and duration (hours per session) throughout the study.

Outcomes collected included interdialytic weight gain (IDWG), pre- and post-dialysis systolic and diastolic blood pressure, and ultrafiltration volume. Blood pressure was performed using the integrated Fresenius Home@K blood pressure monitor with a blood pressure cuff personalized to assure patient fit. Home haemodialysis patients are instructed to measure blood pressure at the beginning and end of haemodialysis treatments, and every 30 minutes during treatments. The cuff is fitted to their arm size, and records blood pressure with the patient relaxed while on haemodialysis. Patients were instructed to report episodes of intradialytic hypotension. Patients were seen in outpatient clinic at a minimum of every three months, during which time other intradialytic or interdialytic symptoms were discussed. Patients also knew to contact the home haemodialysis unit at any time if any urgent concerns arose. IDWG was calculated as the difference between the post-dialysis patient weight and the next dialysis session's pre-dialysis patient weight. Dialysate to pre-dialysis plasma sodium $\left(\mathrm{DPNa}^{+}\right)$and post- to pre-dialysis plasma sodium $\left(\mathrm{PPNa}^{+}\right)$concentration gradients were recorded. We decided a priori that a minimum of 3 observations per study period would be required for each outcome, for a patient to be included in the final analysis. Blood pressure was measured and recorded by patients at home, with automated blood pressure machines, as previously described [34].

\section{Ethics}

Ethics approval was granted by the Western University Health Sciences Research Ethics Board. Informed written consent was obtained from all patients. The study was conducted in accordance with the 1964 Declaration of Helsinki.

Table 1: Background demographic and clinical data.

\begin{tabular}{|c|c|c|c|c|}
\hline & Mean & Median & Standard Deviation & Interquartile Range \\
\hline Number Patients & 27 & & & \\
\hline Age (years) & 54.2 & 54.9 & 11.6 & $48-62$ \\
\hline Sex (\% female) & 40.7 & & & \\
\hline Diabetes (\%) & 33.3 & & & \\
\hline Weight (kg) & 82.9 & 83.1 & 22.7 & $69-92$ \\
\hline Height (cm) & 169.9 & 172 & 12.4 & $165-176$ \\
\hline Body mass index $(\mathrm{kg} / \mathrm{m} 2)$ & 28.6 & 27.7 & 6.6 & $25-32$ \\
\hline Dialysis Frequency (sessions per week) & 4.4 & 4.0 & 1.3 & $3-6$ \\
\hline Dialysis Duration (hours per session) & 4.8 & 4.0 & 2.1 & $3-7$ \\
\hline Vintage (days) & 2539 & 1654 & 2720 & $745-3159$ \\
\hline Residual renal function (mL/min) & 0.51 & 0.00 & 1.25 & $0.00-0.00$ \\
\hline Systolic Blood Pressure (mm Hg) & 136.6 & 131.0 & 23.8 & $121-148$ \\
\hline Diastolic Blood Pressure (mm Hg) & 75.6 & 73.0 & 12.2 & $68-84$ \\
\hline Hemoglobin (g/dL) & 113.2 & 111.0 & 15.6 & $106-121$ \\
\hline Albumin $(g / L)$ & 40.8 & 41.0 & 3.4 & $40-42$ \\
\hline Pre-dialysis Plasma sodium (mmol/L) & 137.3 & 138.0 & 3.5 & $135.5-143.0$ \\
\hline
\end{tabular}

\section{Statistics}

Data were analyzed using the Statistical Package for Social Sciences version 19.0. The mean, median, standard error and interquartile range were calculated for all background demographic and clinical factors.

Statistics-objective 1: Each patient's outcomes were averaged for each study period. Patients' outcomes were then averaged for each study period, and compared using paired two-tailed student T-tests, with a $\alpha$ value of 0.05 considered for statistical significance.

Statistics-objective 2: Pearson correlation coefficients were calculated between each clinical outcome and firstly haemodialysis frequency, then haemodialysis duration. Each patient provided two data points in the analysis, one from each study period. Two-tailed $p$ values with $\alpha$ of 0.05 were used for statistical significance. 
Statistics-objective 3: Pearson correlation coefficients were calculated between each clinical outcome and firstly $\mathrm{DPNa}^{+}$, then PPNa ${ }^{+}$. Two-tailed $p$ values with $\alpha$ of 0.05 were used for statistical significance.

\section{Results}

There were 43 patients screened and approached to participate in the study protocol, 27 of whom consented to participate in the study. A total of 27 patients started and completed both study periods. The mean and median observations were greater than 40 for all clinical outcomes (Interdialytic weight gain, Pre-dialysis and Post-dialysis Blood pressures, Ultrafiltration rate), and greater than 3.0 for each of $\mathrm{DPNa}^{+}$and $\mathrm{PPNa}^{+}$, in both HIGHDialSOD and LOWDialSOD study periods. No patient had fewer than $3 \mathrm{DPNa}^{+}$or $\mathrm{PPNa}^{+}$ measurements in either study period; thus, all patients were included in data analysis. The mean difference between the two averaged monthly Pre- $\mathrm{Na}^{+}$samples, at the beginning of the study, was $0.92 \mathrm{mmol} / \mathrm{L}$, with the majority of differences (24/27) being less than or equal to $2 \mathrm{mmol} / \mathrm{L}$.

The study population's background factors included an average age of 54.2 years, with $40.7 \%$ female and $33.3 \%$ diabetic (Table 1). Dialysis frequency averaged 4.4 sessions per week, with a median of 4.0 weekly sessions. Dialysis duration averaged 4.8 hours per session, with a median of $4.0 \mathrm{~h}$. There were 9 short hours daily, 4 frequent nocturnal, 8 intermittent conventional, and 6 intermittent nocturnal haemodialysis patients, as previously defined [35]. The mean and median pre- dialysis plasma sodium concentration (Pre- $\mathrm{Na}^{+}$) was 137.3 and $138.0 \mathrm{mmol} / \mathrm{L}$, respectively. More than half of study patients had no residual renal function, with a mean of 0.51 and median $0.00 \mathrm{~mL} / \mathrm{min}$.

\section{Objectives}

Objective 1: IDWG (2.15 vs. $1.90 \mathrm{~kg}, \mathrm{p}=0.002)$, IDWG as \% target weight $(2.78$ vs. $2.39 \%, p=0.002)$, pre-dialysis systolic (143.3 vs. $138.3 \mathrm{~mm} \mathrm{Hg}, \mathrm{p}=0.001$ ), diastolic (78.6 vs. $75.6 \mathrm{~mm}$ $\mathrm{Hg}, \mathrm{p}=0.008)$ and mean arterial pressure (100.2 vs. $96.5 \mathrm{~mm} \mathrm{Hg}$, $p=0.003$ ) and post-dialysis systolic (135.4 vs. $130.0, p=0.04)$, diastolic (75.8 vs. 72.4, $\mathrm{p}=0.006)$ and mean arterial pressure (95.7 vs. 91.6, $\mathrm{p}=0.009$ ) were significantly higher in HIGHDialSOD than LOWDialSOD study period (Table 2). No change in target weight, or intradialytic change in systolic, diastolic or mean arterial pressure was found. No episodes of intradialytic hypotension were reported, and thus this outcome was not considered in data analysis.

Objective 2: Haemodialysis frequency was inversely related to IDWG\% ( $R=-0.295$, Slope $=-0.002, \quad P=0.034)$, and positively correlated with post-dialysis diastolic blood pressure $(R=0.366$, slope $=3.464, p=0.008$ ) (Table 3 ). Haemodialysis duration was inversely correlated with ultrafiltration rate $(R=-0.593$, slope $=-0.053, p<0.001)$ and positively correlated with IDWG $(R=0.562$, slope $=0.184, p<0.001)$ IDWG\% $(R=0.507$, slope $=0.002$, $\mathrm{p}<0.001)$ and intradialytic change in diastolic blood pressure $(R=0.280$, slope $=1.127, p=0.044)$.

Table 2: Clinical Endpoints for Home Haemodialysis Patients in HIGHDialSOD and LOWDialSOD Study Periods.

\begin{tabular}{|c|c|c|c|}
\hline & $\begin{array}{l}\text { HIGHDialSOD } \\
\text { PERIOD }\end{array}$ & $\begin{array}{l}\text { LOWDialSOD } \\
\text { PERIOD }\end{array}$ & $\mathbf{P}$ \\
\hline Interdialytic weight gain (kg) & 2.15 & 1.9 & 0.002 \\
\hline Interdialytic weight gain (\% target weight) & 2.78 & 2.39 & 0.002 \\
\hline Target weight (kg) & 82.6 & 83.58 & 0.09 \\
\hline Ultrafiltration rate (L/hour) & 0.49 & 0.44 & 0.006 \\
\hline \multicolumn{4}{|l|}{ Pre-hemodialysis } \\
\hline Systolic blood pressure $(\mathrm{mm} \mathrm{Hg})$ & 143.3 & 138.3 & 0.001 \\
\hline Diastolic blood pressure $(\mathrm{mm} \mathrm{Hg})$ & 78.6 & 75.6 & 0.008 \\
\hline Mean arterial Pressure $(\mathrm{mm} \mathrm{Hg})$ & 100.2 & 96.5 & 0.003 \\
\hline \multicolumn{4}{|l|}{ Post-hemodialysis } \\
\hline Systolic blood pressure $(\mathrm{mm} \mathrm{Hg})$ & 135.4 & 130 & 0.04 \\
\hline Diastolic blood pressure (mm Hg) & 75.8 & 72.4 & 0.006 \\
\hline Mean arterial Pressure $(\mathrm{mm} \mathrm{Hg})$ & 95.7 & 91.6 & 0.009 \\
\hline \multicolumn{4}{|l|}{ Intradialytic change } \\
\hline Systolic blood pressure $(\mathrm{mm} \mathrm{Hg})$ & -7.9 & -8.2 & 0.9 \\
\hline Diastolic blood pressure $(\mathrm{mm} \mathrm{Hg})$ & -3 & -3.2 & 0.76 \\
\hline Mean arterial Pressure $(\mathrm{mm} \mathrm{Hg})$ & -4.6 & -4.9 & 0.8 \\
\hline
\end{tabular}


DialNa ${ }^{+}=$dialysate sodium concentration; $\mathrm{SP}=$ setpoint; $\mathrm{P}$ values calculated as 2 -tailed, paired student's T-test; Bolded text denotes statistical significance $\mathrm{P}<0.05$

Table 3: Correlation between haemodialysis frequency and duration to clinical outcomes.

\begin{tabular}{|c|c|c|c|c|c|c|}
\hline \multirow[b]{2}{*}{ CLINICAL OUTCOME } & \multicolumn{3}{|c|}{ HEMODIALYSIS FREQUENCY } & \multicolumn{3}{|c|}{ HEMODIALYSIS DURATION } \\
\hline & $\mathbf{R}$ & SLOPE & $\mathbf{P}$ & $\mathbf{R}$ & SLOPE & $\mathbf{P}$ \\
\hline Interdialytic weight gain $(\mathrm{kg})$ & -0.228 & -0.119 & 0.097 & 0.562 & 0.184 & $<0.001$ \\
\hline Interdialytic weight gain (\% target weight) & -0.295 & -0.002 & 0.034 & 0.507 & 0.002 & $<0.001$ \\
\hline Ultrafiltration rate (L/hour) & 0.143 & 0.02 & 0.301 & -0.593 & -0.053 & $<0.001$ \\
\hline \multicolumn{7}{|l|}{ Pre-dialysis blood pressure } \\
\hline Systolic (mm Hg) & -0.097 & -1.46 & 0.493 & 0.003 & 0.028 & 0.983 \\
\hline Diastolic (mm Hg) & 0.204 & 1.666 & 0.148 & -0.006 & -0.032 & 0.965 \\
\hline Mean arterial pressure $(\mathrm{mm} \mathrm{Hg})$ & 0.067 & 0.624 & 0.636 & -0.002 & -0.012 & 0.989 \\
\hline \multicolumn{7}{|l|}{ Post-dialysis blood pressure } \\
\hline Systolic (mm Hg) & 0.039 & 0.571 & 0.784 & 0.17 & 1.546 & 0.229 \\
\hline Diastolic (mm Hg) & 0.366 & 3.464 & 0.008 & 0.179 & 1.053 & 0.204 \\
\hline Mean arterial pressure $(\mathrm{mm} \mathrm{Hg})$ & 0.248 & 2.5 & 0.077 & 0.194 & 1.217 & 0.168 \\
\hline \multicolumn{7}{|l|}{ Intradialytic change in blood pressure } \\
\hline Systolic (mm Hg) & 0.166 & 1.96 & 0.239 & 0.21 & 1.534 & 0.136 \\
\hline Diastolic (mm Hg) & 0.262 & 1.698 & 0.06 & 0.28 & 1.127 & 0.044 \\
\hline Mean arterial pressure $(\mathrm{mm} \mathrm{Hg})$ & 0.22 & 1.767 & 0.117 & 0.253 & 1.258 & 0.071 \\
\hline
\end{tabular}

Objective 3: Increased DPNa ${ }^{+}$associated with increased IDWG $(\mathrm{R}=0.346$, slope $=0.001, \mathrm{p}=0.012)$, pre-dialysis diastolic $(\mathrm{R}=0$ 284, slope $=0.824, p=0.041)$ and post-dialysis diastolic $(R=0.325$, slope $=1.084, p=0.019)$ and mean arterial $(R=0.292$, slope $=1.030$, $\mathrm{p}=0.036$ ) blood pressure (Table 3 ). Increased $\mathrm{PPNa}^{+}$associated with increased IDWG $(R=0.306$, slope $=0.001, p=0.029)$ and postdialysis systolic $(R=0.181$, slope $=-0.067, p=0.049)$ blood pressure.

\section{Discussion}

In conventional thrice weekly haemodialysis, positive sodium balance is associated with IDWG, hypertension, left ventricular hypertrophy, cardiovascular morbidity and perhaps mortality $[5,26-30,36,37]$ although the relationship with mortality remains controversial [38]. The clinical effects of frequent or prolonged exposure to sodium concentrations have not been prospectively evaluated. Our study population included patients on quotidian and nocturnal haemodialysis prescriptions (Table 1 ). There were a high proportion of females (40.7\%) and diabetics (33.3\%), and a wide spectrum of other demographic factors such as age and body habitus. Furthermore, each patient had multiple measurements of each clinical outcome in each study period. Thus, our study population was representative of a typical haemodialysis population, and the clinical outcomes were rigorously evaluated.
This study confirms that in a patient group with quotidian and nocturnal haemodialysis patients, personalization of Dial- $\mathrm{Na}$ + higher than SP leads to several undesirable clinical outcomes, including IDWG, pre- and post-dialysis systolic, diastolic and mean arterial pressure (Table 2). This is consistent with previous trials in thrice weekly conventional haemodialysis patients [27-30]. However, there was no difference in intradialytic change in systolic, diastolic or mean blood pressure between HIGHDialSOD and LOWDialSOD study periods. Previous trials in thrice weekly conventional haemodialysis patients have demonstrated that low dialysate sodium increases risk for intradialytic hypotension [39-41]. However intradialytic hypotension occurs when increases in plasma volume from compartments outside plasma occur slower than haemodialysis reduces plasma volume $[40,42]$. Our study population had longer haemodialysis duration than previous trials (mean 4.8 hours, interquartile range 3-7 $\mathrm{h}$ (Table 1 ). Since plasma refilling is dependent upon the ultrafiltration rate, longer haemodialysis likely tapered this effect and decreased the dependence of intradialytic blood pressure changes on dialysate sodium concentration.

Whether and how dialysis frequency or duration modifies the clinical outcomes evaluated in this study is of clinical relevance. Our study confirms three important relationships. Firstly, haemodialysis frequency associates with decreased IDWG $\%$ (Table 3). Consider the common clinical situation of a patient 
undergoing thrice weekly conventional haemodialysis with persistent volume overload and recurrent intradialytic hypotension. Increased dialysis frequency could improve fluid removal $[15,43,44]$ and a slightly positive $\mathrm{DPNa}^{+}$gradient would protect from intradialytic hypotension $[39,41,45]$. Our data provides evidence to support increasing haemodialysis frequency to decrease IDWG in such patients. Secondly, haemodialysis duration associates with an increased IDWG and IDWG\%. While one might hypothesize that this relates to more prolonged exposure to a $\mathrm{DNa}^{+}$gradient, the gradient was positive in the HIGHDialSOD, but not in the LOWDialSOD study period. Therefore, this could reflect the common practice of avoiding food and drink during haemodialysis; this would disrupt dietary intake for conventional and quotidian, but not nocturnal patients. Thirdly, haemodialysis duration associated with increased intradialytic fall in diastolic blood pressure. Previous research has consistently shown that increased haemodialysis time decreases ultrafiltration rate and risk of intradialytic hypotension $[22,27,39,46]$ contrary to this study's findings. However, nocturnal haemodialysis patients often sleep during haemodialysis, so post-dialysis blood pressure is measured in the morning in a relaxed state, unlike the shorter haemodialysis sessions in conventional dialysis. Therefore, the intradialytic blood pressure change may relate also to vasomotor tone, rather than ultrafiltration rates.

$\mathrm{DPNa}^{+}$was superior to $\mathrm{PPNa}{ }^{+}$in predicting IDWG\%, predialysis diastolic, post-dialysis diastolic and mean arterial pressure (Table 3 ). This data is in contrast to a number of trials that suggest $\mathrm{PPNa}^{+}$to be more predictive $[30,47,48]$. Plasma $\mathrm{Na}^{+}$ approaches Dial- $\mathrm{Na}^{+}$throughout hemodialysis, so intradialytic change in plasma $\mathrm{Na}^{+}$was predicted to be less than $3 \mathrm{mmol} / \mathrm{L}$ in our study, since Dial- $\mathrm{Na}^{+}$was randomized to be $3 \mathrm{mmol} / \mathrm{L}$ above (HIGHDialSOD) or below (LOWDialSOD) the SP. Indeed, mean $\mathrm{PPNa}^{+}$was quite low in our study (LOWDialSOD PPNa ${ }^{+}=-1.08$ $\mathrm{mmol} / \mathrm{L}$; HIGHDialSOD PPNa $\left.{ }^{+}=0.57 \mathrm{mmol} / \mathrm{L}\right)$, so $\mathrm{PPNa}^{+}$was too small to overcome the lack of precision in the plasma $\mathrm{Na}+$ measurement. However, use of the $\mathrm{PPNa}^{+}$gradient has the disadvantage of using Post- $\mathrm{Na}^{+}$and therefore not being known prior to a hemodialysis session. Knowing that DPNa+ predicts clinical outcomes better than PPNa${ }^{+}$when Dial- $\mathrm{Na}^{+}$is $3 \mathrm{mmol} / \mathrm{L}$ above or below the SP provides useful information, and helps guide selection of dialysate sodium to improve clinical outcomes. Furthermore, it makes measuring Post- $\mathrm{Na}^{+}$ unnecessary so long as Dial- $\mathrm{Na}^{+}$is within $3 \mathrm{mmol} / \mathrm{L}$ of the Pre- $\mathrm{Na}$

This study does have limitations. Firstly, we did not record dialysis membrane surface area or blood glucose [49-52], each of which can impact diffusive sodium balance on haemodialysis. However, use of a randomized crossover design negated these effects, since each patient served as their own control, and since these factors were unlikely to change for any particular patient between study periods. Secondly, our study population was small. Despite this, an abundance of clinical endpoints and numerous pre- and post-dialysis sodium values were available from all patients on multiple dialysis modalities. We were still able to report important outcomes of statistical and clinical significance. Thirdly, while both intradialytic hypotension and IDWG correlate with increased mortality [4,5,42], higher dialysate sodium associates with decreased mortality in a subgroup of conventional haemodialysis patients [38]. Therefore, the precise relationship between clinical outcomes and survival still requires prospective evaluation in patients prescribed haemodialysis of varying frequency and duration. This is the first prospective evaluation of the effect of varying dialysate sodium concentrations on clinical outcomes in conventional, nocturnal and short hour's daily haemodialysis patients.

\section{Conclusion}

In conclusion, higher personalized dialysate sodium concentration lead to increased interdialytic weight gain, preand post-dialysis blood pressure, and ultrafiltration rates in a patient population that includes conventional, quotidian, and nocturnal haemodialysis patients. While haemodialysis frequency associates with decreased IDWG\%, the opposite relationship is seen with haemodialysis duration. Furthermore, longer haemodialysis leads to greater falls in diastolic blood pressure, counter to previous research findings. $\mathrm{DPNa}^{+}$gradient is preferable to $\mathrm{PPNa}^{+}$to predict clinical outcomes so long as the Dial- $\mathrm{Na}^{+}$is personalized within $3 \mathrm{mmol} / \mathrm{L}$ of the SP. Further work is needed to establish the effect of personalizing the dialysate sodium concentrations on long-term cardiovascular outcomes in quotidian and nocturnal haemodialysis patients.

\section{Acknowledgement}

This work was funded in part from a grant from the Program of Experimental Medicine at Western University. Salary support for author BT was provided by the Clinical Investigator Program at Western University.

\section{References}

1. Tong A, Palmer S, Manns B, Craig JC, Ruospo M, et al. (2013) The beliefs and expectations of patients and caregivers about home haemodialysis: an interview study. BMJ Open 3.

2. Paoletti E, Specchia C, Di Maio G, Bellino D, Damasio B, et al. (2004) The worsening of left ventricular hypertrophy is the strongest predictor of sudden cardiac death in haemodialysis patients: a 10 year survey. Nephrol Dial Transplant 19: 1829-1834.

3. Parfrey PS, Foley RN, Harnett JD, Kent GM, Murray DC, et al. (1996) Outcome and risk factors for left ventricular disorders in chronic uraemia. Nephrol Dial Transplant 11: 1277-1285.

4. Kalantar-Zadeh K, Regidor DL, Kovesdy CP, Van Wyck D, Bunnapradist S, et al. (2009) Fluid retention is associated with cardiovascular mortality in patients undergoing long-term hemodialysis. Circulation 119: 671-679.

5. Kimmel PL, Varela MP, Peterson RA, Weihs KL, Simmens SJ, et al. (2000) Interdialytic weight gain and survival in hemodialysis patients: effects of duration of ESRD and diabetes mellitus. Kidney Int 57: 1141-1151.

6. Chan CT, Greene T, Chertow GM, Kliger AS, Stokes JB, et al. (2012) Determinants of left ventricular mass in patients on hemodialysis: Frequent Hemodialysis Network (FHN) Trials. Circ Cardiovasc Imaging 5: 251-261. 
7. Foley RN, Curtis BM, Randell EW, Parfrey PS (2010) Left ventricular hypertrophy in new hemodialysis patients without symptomatic cardiac disease. Clin J Am Soc Nephrol 5: 805-813.

8. Khangura J, Culleton BF, Manns BJ, Zhang J, Barnieh L, et al. (2010) Association between routine and standardized blood pressure measurements and left ventricular hypertrophy among patients on hemodialysis. BMC Nephrol 11: 13.

9. Koc $Y$, Unsal A, Kayabasi H, Oztekin E, Sakaci T, et al. (2011) Impact of volume status on blood pressure and left ventricle structure in patients undergoing chronic hemodialysis. Ren Fail 33: 377-381.

10. Wald R, Goldstein MB, Wald RM, Harel Z, Kirpalani A, et al. (2014) Correlates of left ventricular mass in chronic hemodialysis recipients. Int J Cardiovasc Imaging 30: 349-356.

11. London GM, Pannier B, Guerin AP, Blacher J, Marchais SJ, et al. (2001) Alterations of left ventricular hypertrophy in and survival of patients receiving hemodialysis: follow-up of an interventional study. J Am Soc Nephrol 12: 2759-2767.

12. Devereux RB, Wachtell K, Gerdts E, Boman K, Nieminen MS, et al. (2004) Prognostic significance of left ventricular mass change during treatment of hypertension. Jama 292: 2350-2356.

13. Lindsay RM (2004) The London, Ontario, Daily/Nocturnal Hemodialysis Study. Semin Dial 17: 85-91.

14. Rocco MV, Lockridge RS, Jr., Beck GJ, Eggers PW, Gassman JJ, et al. (2011) The effects of frequent nocturnal home hemodialysis: the Frequent Hemodialysis Network Nocturnal Trial. Kidney Int 80: 1080-1091.

15. Culleton BF, Walsh M, Klarenbach SW, Mortis G, Scott-Douglas N, et al. (2007) Effect of frequent nocturnal hemodialysis vs conventional hemodialysis on left ventricular mass and quality of life: a randomized controlled trial. JAMA 298: 1291-1299.

16. Daugirdas JT, Chertow GM, Larive B, Pierratos A, Greene T, et al. (2012) Effects of frequent hemodialysis on measures of CKD mineral and bone disorder. J Am Soc Nephrol 23: 727-738.

17. Mucsi I, Hercz G, Uldall R, Ouwendyk M, Francoeur R, et al. (1998) Control of serum phosphate without any phosphate binders in patients treated with nocturnal hemodialysis. Kidney Int 53: 1399-1404.

18. Schwartz DI, Pierratos A, Richardson RM, Fenton SS, Chan CT (2005) Impact of nocturnal home hemodialysis on anemia management in patients with end-stage renal disease. Clin Nephrol 63: 202-208.

19. Barua $M$, Hladunewich $M$, Keunen J, Pierratos $A$, McFarlane $P$, et al. (2008) Successful pregnancies on nocturnal home hemodialysis. Clin J Am Soc Nephrol 3: 392-396.

20. Johansen KL, Zhang R, Huang Y, Chen SC, Blagg CR, et al. (2009) Survival and hospitalization among patients using nocturnal and short daily compared to conventional hemodialysis: a USRDS study. Kidney Int 76: 984-990.

21. Lacson E, Jr., Xu J, Suri RS, Nesrallah G, Lindsay R, et al. (2012) Survival with three-times weekly in-center nocturnal versus conventional hemodialysis. J Am Soc Nephrol 23: 687-695.

22. Saran R, Bragg-Gresham JL, Levin NW, Twardowski ZJ, Wizemann $V$, et al. (2006) Longer treatment time and slower ultrafiltration in hemodialysis: associations with reduced mortality in the DOPPS. Kidney Int 69: 1222-1228.

23. Peixoto AJ, Gowda N, Parikh CR, Santos SF (2010) Long-term stability of serum sodium in hemodialysis patients. Blood Purif 29: 264-267.
24. Keen ML, Gotch FA (2007) The association of the sodium "setpoint" to interdialytic weight gain and blood pressure in hemodialysis patients. Int J Artif Organs 30: 971-979.

25. Farmer CK, Hobbs H, Mann S, Newall RG, Ndawula E, et al. (2000) Leukocyte esterase reagent strips for early detection of peritonitis in patients on peritoneal dialysis. Perit Dial Int 20: 237-239.

26. Lambie SH, Taal MW, Fluck RJ, McIntyre CW (2005) Online conductivity monitoring: validation and usefulness in a clinical trial of reduced dialysate conductivity. Asaio J 51: 70-76.

27. de Paula FM, Peixoto AJ, Pinto LV, Dorigo D, Patricio PJ, et al. (2004) Clinical consequences of an individualized dialysate sodium prescription in hemodialysis patients. Kidney Int 66: 1232-1238.

28. Thein H, Haloob I, Marshall MR (2007) Associations of a facility level decrease in dialysate sodium concentration with blood pressure and interdialytic weight gain. Nephrol Dial Transplant 22: 2630-2639.

29. Sayarlioglu H, Erkoc R, Tuncer M, Soyoral Y, Esen R, et al. (2007) Effects of low sodium dialysate in chronic hemodialysis patients: an echocardiographic study. Ren Fail 29: 143-146.

30. Hecking $M$, Kainz A, Horl WH, Herkner $H$, Sunder-Plassmann $G$ (2011) Sodium setpoint and sodium gradient: influence on plasma sodium change and weight gain. Am J Nephrol 33: 39-48.

31. Munoz Mendoza J, Bayes LY, Sun S, Doss S, Schiller B (2011) Effect of lowering dialysate sodium concentration on interdialytic weight gain and blood pressure in patients undergoing thrice-weekly incenter nocturnal hemodialysis: a quality improvement study. Am J Kidney Dis 58: 956-963.

32. Locatelli F, Di Filippo S, Manzoni C (2000) Relevance of the conductivity kinetic model in the control of sodium pool. Kidney Int Suppl 76: S89-S95.

33. Levey AS, Bosch JP, Lewis JB, Greene T, Rogers N, et al. (1999) A more accurate method to estimate glomerular filtration rate from serum creatinine: a new prediction equation. Modification of Diet in Renal Disease Study Group. Ann Intern Med 130: 461-470.

34. Agarwal R, Brim NJ, Mahenthiran J, Andersen MJ, Saha C (2006) Out-of-hemodialysis-unit blood pressure is a superior determinant of left ventricular hypertrophy. Hypertension 47: 62-68.

35. Thomson BK, Huang SH, Chan CT, House AA, Lindsay RM (2013) Plasma sodium setpoint: is it constant or changed by hemodialysis prescription? Asaio J 59: 497-504.

36. Kayikcioglu M, Tumuklu M, Ozkahya M, Ozdogan O, Asci G, et al. (2009) The benefit of salt restriction in the treatment of end-stage renal disease by haemodialysis. Nephrol Dial Transplant 24: 956-962.

37. Foley RN, Herzog CA, Collins AJ (2002) Blood pressure and longterm mortality in United States hemodialysis patients: USRDS Waves 3 and 4 Study. Kidney Int 62: 1784-1790.

38. Hecking M, Karaboyas A, Saran R, Sen A, Horl WH, et al. (2012) Predialysis serum sodium level, dialysate sodium, and mortality in maintenance hemodialysis patients: the Dialysis Outcomes and Practice Patterns Study (DOPPS). Am J Kidney Dis 59: 238-248.

39. Sherman RA (2001) Modifying the dialysis prescription to reduce intradialytic hypotension. Am J Kidney Dis 38: S18-S25.

40. Agarwal R (2012) How can we prevent intradialytic hypotension? Curr Opin Nephrol Hypertens 21: 593-599.

41. Suckling RJ, Swift PA, He FJ, Markandu ND, MacGregor GA (2013) Altering plasma sodium concentration rapidly changes blood 
pressure during haemodialysis. Nephrol Dial Transplant 28: 2181-2186.

42. Henderson LW (2012) Symptomatic intradialytic hypotension and mortality: an opinionated review. Semin Dial 25: 320-325.

43. Chertow GM, Levin NW, Beck GJ, Depner TA, Eggers PW, et al. (2010) In-center hemodialysis six times per week versus three times per week. N Engl J Med 363: 2287-2300.

44. Suri RS, Nesrallah GE, Mainra R, Garg AX, Lindsay RM, et al. (2006) Daily hemodialysis: a systematic review. Clin J Am Soc Nephrol 1: 33-42.

45. Agarwal R (2013) B-type natriuretic peptide is not a volume marker among patients on hemodialysis. Nephrol Dial Transplant 28: 3082-3089.

46. Jefferies HJ, Virk B, Schiller B, Moran J, McIntyre CW (2011) Frequent hemodialysis schedules are associated with reduced levels of dialysis-induced cardiac injury (myocardial stunning). Clin J Am Soc Nephrol 6: 1326-1332.

47. Hecking M, Karaboyas A, Saran R, Sen A, Inaba M, et al. (2012) Dialysate sodium concentration and the association with interdialytic weight gain, hospitalization, and mortality. Clin J Am Soc Nephrol 7: 92-100.

48. Thomson BK, Huang SH, Leitch RE, Dixon S, Heidenheim P, et al. (2013) Pre to post-dialysis plasma sodium change better predicts clinical outcomes than dialysate to plasma sodium gradient in quotidian hemodialysis. Hemodial Int 17: 548-556.

49. Pries AR, Neuhaus D, Gaehtgens P (1992) Blood viscosity in tube flow: dependence on diameter and hematocrit. Am J Physiol 263:H1770-1778.

50. Depner T, Daugirdas J, Greene T, Allon M, Beck G, et al. (2004) Dialysis dose and the effect of gender and body size on outcome in the HEMO Study. Kidney Int 65: 1386-1394.

51. Katz MA (1973) Hyperglycemia-induced hyponatremia--calculation of expected serum sodium depression. N Engl J Med 289: 843-844.

52. Rothman SS (1980) Passage of proteins through membranes--old assumptions and new perspectives. Am J Physiol 238: G391-402. 